\title{
Right Anterolateral Thoracotomy an Alternative to Median Sternotomy for Closure of Atrial Septal Defect: A Cosmetic Approach in Young Females
}

\author{
Ravi Kumar Baral ${ }^{1}$, Bhagawan Koirala ${ }^{1}$ \\ ${ }^{\prime}$ Department of Cardiothoracic and Vascular surgery Manmohan Cardiovascular \\ Thoracic and Transplant Center (MCVTC), Institute of Medicine, Maharajgunj, Kathmandu.
}

\section{Citation}

Ravi Kumar Baral, Bhagawan Koirala. Right Anterolateral Thoracotomy an Alternative to Median Sternotomy for Closure of Atrial Septal Defect: A Cosmetic Approach in Young Females Nepalese Heart Journal 2015; 12 (1): 21-25

\section{Key words}

Atrial septal defects; median sternotomy; right anterolateral thoracotomy.

\section{INTRODUCTION}

Atrial Septal Defect (ASD) closure is common cardiac operation performed worldwide. Median sternotomy[MS] is a safe approach adopted by many surgeons as a gold standard for cardiac surgery. Mortality for ASD closure from this approach is nearly $0 \%,{ }^{1-4} \cos m e s i s$ has now become a concern to surgeons and patients especially among young females. We tried to

\section{ABSTRACT}

Background and Aims: Atrial septal defect operation is a safe and low-risk procedure. Cosmetic results have been an important issue, so right anterolateral thoracotomy approach has been used for repair. We present minimally invasive ASD closure via limited right anterolateral thoracotomy, as our early experience in road of minimally invasive cardiac surgery.

Methods: This study was done in the Manmohan Cardiothoracic and Transplant Center in the time period of 2012 to 2013. The study included 70 patients aged 15 - 35 years old (22.1 \pm 5.5$)$ admitted for surgical repair of their secundum atrial septal defects. The patients were randomly allocated into one of two groups according to the approach used in their operation. Right anterolateral thoracotomy(RALT) group included 35 patients operated via right anterolateral thoracotomy.and median sternotomy(MS) group included 35 patients operated via the median sternotomy.

Result: Of 70 patients only 63 patients meet the criteria for analysis. There was no statistically significant difference between the 2 groups regarding their demographic data and duration of operation. Postoperative pleural/pericardial effusion and pneumothorax occurred in $2.1 \%$ of patients in MS and $6.6 \%$ in Right anterolateral thoracotomygroup $(p=0.001)$. Total in hospital pain score was high in sternotomy group than thoracotomy group, but did not reach statistically significant values. There was no operative or late mortality or morbidity in the early follow-up (range, $1 \mathrm{~m}$ to 2 years, mean $1.34 \mathrm{yrs}$ ).

Conclusion: RALT is a safe and effective alternative approach to MS incision for ASD closure.

\section{Corresponding Author}

\section{Ravi Kumar Baral}

Department of Cardiothoracic and Vascular surgery Manmohan Cardiovascular Thoracic and Transplant Center (MCVTC),

Institute of Medicine, Maharajgunj, Kathmandu.

Email: ravi.baral4@gmail.com 
compare the surgical and cosmetic outcome in Right Anterolateral Thoracotomy (RALT) approach with standard MS approach.

Trans-catheter closure of ASD is safe and widely accepted approach with best cosmetic outcome. This approach is not applicable to all cases of ASD because of various reasons..$^{2-6}$ In our center cost and expertise apart from these reasons is an issue in application of this approach so surgical closure remains the therapy of choice. MS with cardiopulmonary bypass is a standard procedure performed in our center. Currently more and more emphasis is put on the cosmetic result of surgical closure.

RALT is commonly described approach apart from MS for closure of ASD with comparable outcome and safety. It is discussed that this approach is not safe in complex lesion and has more pain and an increased incidence of phrenic nerve damage. ${ }^{7}$ In this study we review our initial experience with use of RALT for ASD closure. The demographic profiles, duration of surgery, pain score and cosmetic satisfaction were observed.

\section{METHODS}

This is a prospective randomized study done in department of cardiothoracic vascular surgery of Manmohan Cardiothoracic Vascular and Transplant Center, Institute of Medicine (IOM), Tribhuwan University. This study was done over a period of two year 2012 and 2013. All young females between 15 to 35 years admitted for surgical closure of ASD were included. Male patients, females of age less than 15 and more than 35 years operated for ASD closure were excluded. Randomization was done by using lottery method for the allocation of patients to either MS group or RALT group. Informed consent from the patient was taken and the study was approved from the Institutional review board.

\section{OPERATIVE}

\section{TECHNIQUES:}

\section{MEDIAN STERNOTOMY (MS):}

Standard anterior midline incision was made from suprasternal notch up to Xipsternum. Pericardial patch prepared and aortobicaval cannulation with caval snares was used to establish cardiopulmonary bypass. Right atrium opened $2 \mathrm{~cm}$ lateral to the atrioventricular groove extending from right atrial appendage superiorly to anterior to the inferior Venacava inferiorly. ASD closed with autologous untreated pericardial patch. RA was closed in 2 layers and chest closed with a single ventricular pacing wire and mediastinal drain. The lady giving consent were randomized using lottery system.

Right Anterolateral Thoracotomy (RALT, figure 1):

The patients were placed in supine position with pillow below right shoulder to elevate right side up by 45 degrees off the operating table. Submammary incision of 10 to $12 \mathrm{~cm}$ length was made right pleural space entered from 4th intercostal space and aortobicaval cannulation was done in seven initial cases. Aortic and IVC cannula were shifted to right groin and Superior venacava cannula shifted to percutaneous jugular cannula in later cases which help in decreasing the incision length from more than $10 \mathrm{~cm}$ in initial cases to $5-8 \mathrm{~cm}$ in later MALT (mini right anterolateral thoracotomy figure 2) cases. Autologous pericardial patch was prepared and both cavae snared. Right atrium opened $2 \mathrm{~cm}$ lateral to the atrioventricular groove extending from right atrium appendage superiorly to anterior to the inferior Venacava inferiorly. ASD closed with autologous untreated pericardial patch. RA was closed in 2 layers and chest closed with a single ventricular pacing wire and right pleural drain. An extra-pleural catheter was placed passing from $3 \mathrm{rd}$ to 5 th space for analgesic purpose.

Data regarding demography, symptomatology, operative time, complications, pain scores and cosmetic satisfaction were recorded and analyzed with SPSS 17. P-value of $\leq 0.05$ was considered significant.

\section{RESULTS}

Seventy females were admitted for surgical closure of ASD in department over period of two year. They were divided into two groups Median 
Sternotomy group and Right Anterolateral

Table 1. Demography in two groups.

\begin{tabular}{|l|l|l|l|} 
& $\begin{array}{l}\text { Median } \\
\text { Sternotomy }\end{array}$ & $\begin{array}{l}\text { Rightan- } \\
\text { terolateral } \\
\text { thoracotomy }\end{array}$ & P value \\
\hline $\begin{array}{l}\text { Age } \\
\text { (years) }\end{array}$ & $23.22 \pm 5.43$ & $20.97 \pm 5.04$ & 0.692 \\
\hline $\begin{array}{l}\text { Weight } \\
\text { (KG) }\end{array}$ & $51.55 \pm 10.66$ & $48.2 \pm 9.3$ & 0.398 \\
\hline
\end{tabular}

Table 2. Intraoperative and postoperative parameters with incision type.

\begin{tabular}{|l|l|l|l|}
\hline & MS & RALT & P value \\
\hline $\begin{array}{l}\text { Operative time } \\
\text { (minutes) }\end{array}$ & $122.3 \pm 38.1$ & $148.0 \pm 51.4$ & 0.028 \\
\hline $\begin{array}{l}\text { Extra corporeal } \\
\text { circulation time } \\
\text { (minutes) }\end{array}$ & $32.9 \pm 9.4$ & $31.1 \pm 5.9$ & 0.360 \\
\hline $\begin{array}{l}\text { Closure time } \\
\text { (minutes) }\end{array}$ & $67.8 \pm 37.5$ & $36.4 \pm 15.9$ & 0.001 \\
\hline $\begin{array}{l}\text { Drain } \\
\text { (milliliter) }\end{array}$ & $268.4 \pm 230.1$ & $142.6 \pm 102.3$ & 0.007 \\
\hline $\begin{array}{l}\text { Transfusion } \\
\text { requirement } \\
\text { (Unit) }\end{array}$ & $2.8 \pm 1.5$ & $1.74 \pm 1.50$ & 0.005 \\
\hline ICU stay (days) & $2.3 \pm 1.3$ & $1.4 \pm 0.5$ & 0.001 \\
\hline $\begin{array}{l}\text { Hospital stay } \\
\text { (days) }\end{array}$ & $4.7 \pm 1.2$ & $4.3 \pm 1.2$ & 0.194 \\
\hline
\end{tabular}

Thoracotomy group by lottery system. Seven patients were excluded from the study due to loss of medical records. There were 31 patients in RALT group and 32 patients in MS group for analysis. Both the groups were comparable for age and weight as shown in table 1. All patients in both group had shortness of breath of NYHA I or II. All pat Overall operative time was significantly higher in RALT group (148.0 \pm 51.4 minutes) than MS group (122.3 \pm 38.1 minutes) and was statistically significant $(\mathrm{p}=0.028)$. Extracorporeal circulation and overall hospital stay are similar in both the groups (table 2). The chest closure time after decannulation, amount of the drain postoperatively and the transfusion requirement were significantly lower in the RALT group [table 2]. Though $55.8 \%$ of patients in RALT group had pain score of more than 5, there was no statistically significant difference when compared with the MS group ( $p$ value of
0.062) may be because of the use of extrapleural catheter and continuous infusion of analgesics in postoperative period in RALT group. Only intravenous and oral analgesics were used in the MS group. Majority of the patients in RALT group were satisfied with their cosmetic outcome which was statistically significant $(\mathrm{p}=0.0001)$.

There were few complications in both the groups ( listed in table 3). The complication specific to the new access RALT is femoral artery narrowing at the arterial cannulation site used in RALT group patients, which occurred in $2(6.45 \%)$ patients. Pericardial effusion and mediastinal bleeding was common in MS group. One patient in MS group required exploration for excessive mediastinal bleeding and a patient required pericardial drainage for tamponade.

\section{DISCUSSION}

ASD closure is a safe procedure with mortality nearing zero.8This achievement in ASD closure by standard median sternotomy approach has evolved the thought of more cosmetic approach for closure of ASD. Percutaneous device closure of the ASD is a standard minimally invasive approach with very satisfactory outcome for ASD closure but is not applicable in all cases of ASD. Difficulty in establishing extracorporeal circulation, long operating time and the pain of thoracotomy were of concerns to many surgeons.1,7-8Hidden scar beneath the mammary fold has been the most satisfying cosmetic outcome after ASD closure from the thoracotomy approach. All patients (35/35) in RALT group were completed with this approach without any conversion, which is comparable with many series with conversion rate from 0 to 1\%. 6-9overall operating time and establishment of the extracorporeal circulation was found to be long in RALT group which could be attributed to early learning curve of the surgical team, as this time has decreased in cases done later. Aortic cross clamp time and cardiopulmonary bypass time are both similar RALT $(31 . \pm 5.1$ minutes) vs $\mathrm{MS}(32.9 \pm 9.4$ minutes $)$ in two groups and comparable to other studies.2-3 Mediastinal bleeding and transfusion requirement are higher in MS group most probably owning to the larger raw sternal surface area. Pain score in our 
study was low in both the groups which could be attributed to the routine use of extra-pleural catheter and the continuous analgesics infusion in the thoracotomy group. Cosmetic satisfaction was $94 \%$ in RALT group of our study; two patients unsatisfied of the cosmetic outcome were one with keloid in the medial end of the scar and the other deformed breast contour due to the scar contracture. These deformed breast contours is highly reported in many series as a complication which is lacking in our study may be because of the short follow up time and most ladies they don't complaint of the deformity. ${ }^{10}$ There were no complications in intraoperative period. Atrial fibrillation and supra ventricular tachy-arrhythmia are less in RALT group (3.2\%) as reported by many series ranging from 2.5 to $13 \% .{ }^{11}$ All the complications in our series were not specific to any approach except two femoral artery stenosis unique to the RALT group which was detected in operating room and managed with patch augmentation \& resection with end to end anastomosis.

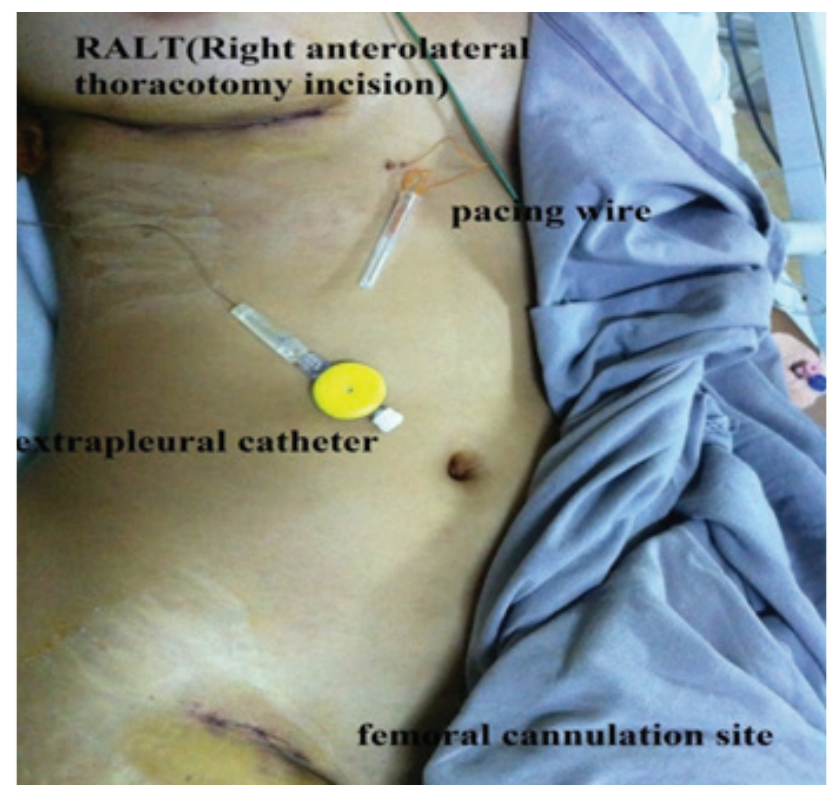

Figure 1. Right anterolateral incision with pacing wire and extrapleural catheter in situ.
This study included only young female which does not reflect all ASD closure patients. We have changed from right anterolateral thoracotomy to the mini right anterolateral thoracotomy with or without peripheral cannulation; this lack of uniformity might have altered some of the findings of this study. Though early reports showed an encouraging result we lack long term follow up and data about long term complications like chronic neurogenic pain, breast deformity etc. RALT is safer in person with well developed breast and is better avoided in pubertal age group.

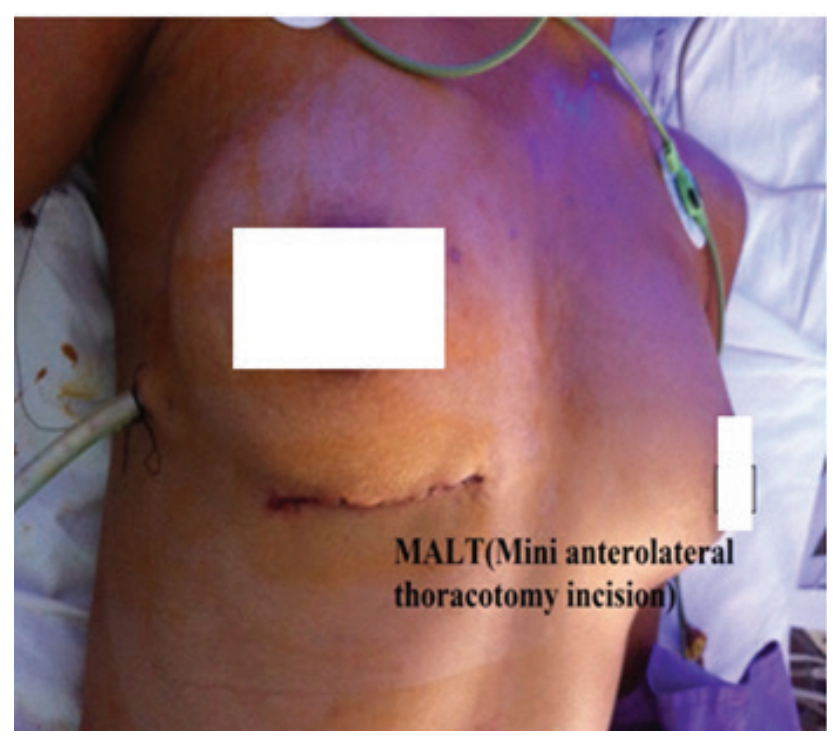

Figure 2. Mini anterolateral thoracotomy in a 16 year old girl

\section{CONCLUSION}

RALT is a safe and acceptable surgical approach for closure of ASD. Experience of pain is almost similar to the MS group with routine use of the extra-pleural catheter with continuous analgesic infusion. RALT is a cosmetically superior approach owning to the hidden submammary scar but long term outcome regarding to the breast related complication should be considered especially in adolescent females. 


\section{REFERENCES}

1 Kumar AS, Prasad S, Rai S, Saxena DK. Right thoracotomy revisited.Texas Heart Inst J 1993;20:40-42.

2 Lancaster LL, Mavroudis C, Rees AH, Slater AD, Ganzel BL, GrayLA. Surgical approach to atrial septal defect in female.Right thoracotomyversus sternotomy. Am Surg 1990;56:218-221.

3 Massetti M, Babatasi G, Rossi A, Neri E, Bhoyroo S, Zitouni S,Maragnes P, Khayat A. et al Operation for atrial septal defect through aright anterolateral thoracotomy: Current outcome. Ann ThoracSurg1996;62:1100-1103.

4 Schmid FX, Wippermann CF, Hake U, Mayer E, Kupferwasser I,Schranz D, et al Surgical closure of atrial septal defects viaright-sided thoracotomy. Value with reference to the developmentof interventional closure techniques. Z Kardiol 1996;85 (7):489-494.

5 Lloyd TR, Rao PS, Beekman RH, Mendelsohn AM, Sideris EB. Atrial septal defect occlusion with the buttoned device: a multi-institutional US trial. Am J Cardiol 1994;73:286-291.

6 Perry SB, Van der Velde ME, Bridges ND, Keane JF, Lock JE. Transcatheter closure of atrial and ventricular septal defects.Herz 1993;18:135-142.

7 Helps B-A, Ross-Russel RI, Dicks-Mireau C, Elliott MJ. Phrenic nerve damage via a right thoracotomy in older children with secundum ASD. Ann ThoracSurg 1993;56:328-330.

8 Todd K, Rosengart TK, Stark JF. Repair of atrial septal defect through a right thoracotomy. Ann ThoracSurg 1993;55:1138-1140.

9 Tribble CG, Killinger WA, Harman K, Crosby IK, Nolan AP, Kron IL. Anterolateral thoracotomy as an alternative to repeat median sternotomy for replacement of the mitral valve. Ann ThoracSurg 1987;43:380-382.

10 Bleiziffer S, Schreiber Ch, Burgkart R, Regenfelder F, Kostolny M, Libera P, et al. The influence of right anterolateral thoracotomy in prepubescent female patients on late breast development and on the ncidence of scoliosis. J ThoracCardiovascSurg2004; 127: 1474-1480.

11 Grinda JM, Folliguet TA, Dervanian P, Mace' L, Legault B, Neveux JY. Right anterolateral thoracotomy for repair of atrial septal defect. Ann ThoracSurg 1996;62:175-178. 